Journal of Scientific Perspectives

Volume 3, Issue 3, Year 2019, pp. 165-176

E - ISSN: 2587-3008

URL: http://ratingacademy.com.tr/ojs/index.php/jsp

DOI: https://doi.org/10.26900/jsp.3.017

Research Article

\title{
THE SYNTHESIS OF SPHERICAL SHAPE AMINO FUNCTIONALIZED PEI-TGIC COVALENT ORGANIC FRAMEWORKS: SYNTHESIS, CHARACTERIZATION, AND METHYL ORANGE ABSORPTION
}

\author{
Sahin DEMIRCI * \& Coskun SILAN ** \& Selehattin YILMAZ *** \\ * Nanoscience and Technology Research and Application Center (NANORAC), Canakkale \\ Onsekiz Mart University, TURKEY, e-mail: sahindemirci@gmail.com \\ ORCID: http://orcid.org/0000-0001-7083-1481 \\ **Assoc. Prof. Dr., Faculty of Medicine, Department of Pharmacology, Canakkale Onsekiz Mart \\ University, TURKEY, e-mail: csilan@hotmail.com \\ ORCID ID: https://orcid.org/0000-0002-8352-6571 \\ *** Prof.Dr. Department of Chemistry, Faculty of Science \& Arts, Canakkale Onsekiz Mart \\ University, TURKEY, e-mail: seletyilmaz@hotmail.com \\ ORCID ID: https://orcid.org/0000-0003-4607-3523
}

Received: 27 June 2019; Accepted: 17 July 2019

\begin{abstract}
In here, the synthesis of covalent organic framework (COF) from the reaction of polyethyleneimine (PEI) and triglycidyl isocyanurate (TGIC) in dimethylformamide at $90{ }^{\circ} \mathrm{C}$ were carried out. The surface are, pore volume and pore size values of PEI-TGIC COFs observed as 23.4 $\mathrm{m}^{2} / \mathrm{g}, 0.143 \mathrm{~cm}^{3} / \mathrm{g}$, and $22.5 \mathrm{~nm}$, respectively. Moreover, the surface charge of PEI-TGIC COFs increased to $+46.1 \pm 2.6 \mathrm{mV}$ from $+18.3 \pm 1.7 \mathrm{mV}$, after protonation of amine groups of PEI-TGIC COFs. Moreover, the potential usage of PEI-TGIC based COFs in absorption methyl orange (MO) dye from aqueous media was testing. It was observed that, the PEI-TGIC COF absorbed 156.6 $4.9 \mathrm{mg} / \mathrm{g} \mathrm{MO}$, and the protonated PEI-TGIC (p-PEI-TGIC) COFs absorbed $202.4 \pm 5.3 \mathrm{mg} / \mathrm{g}$ MO from aqueous media in 30 min. The MO absorption by PEI-TGIC COF fitted with pseudo-first-order kinetic model, whereas MO absorption by p-PEI-TGIC COF fitted with pseudo-second-order kinetic model.
\end{abstract}

Keywords: Covalent organic framework, COF, PEI-TGIC, methyl orange absorption 


\section{INTRODUCTION}

In recent years, scientists have set out from nature's ability to create complex systems; have made great progress in the production of many materials with advanced functions by combining units in different shapes and structures [1-3]. By way of example, many materials have been synthesized from zero dimension materials [4] to three-dimensional materials [5], inorganic materials [6] to organic materials [7], irregular amorphous materials [8] to regular crystalline materials [9], non-porous materials [10] and porous materials [11] by using weak bonds such as p-p bonds [12] and stronger bonds such as covalent bonds [13]. For porous structure synthesis, exciting progress has been made in coordination chemistry and material science, and metal organic frameworks (MOFs), which are coordinated polymers have been synthesized using metal ions and organic ligands [5]. In addition, with recent significant developments, new generation amorphous materials of various pore sizes have been synthesized such as hyper crosslinked polymers (HCPs) [14], internal microporous polymers (PIMs) [15], conjugated microporous polymers (CMPs) [16], cryogels [17] and son on [18]. With these developments in the synthesis of porous structures; the synthesis of covalently bonded crystalline porous structures has been a new field of research for researchers. Studies have shown that the most important strategy for this purpose is the use of rigid units with multiple connections by covalent bonds [19]. Finally, in 2005, the first covalent organic frameworks (COFs) were synthesized by Yaghi and co-workers, with crystallin, and porous structure and high surface area [7].In brief, COFs are two- or three-dimensional porous crystal structures synthesized by regulation of organic subunits [7, 20,21]. Although they were used for gas absorption [22] and separation [23] when first synthesized, advances in this area have enabled COFs to be used in a wide range of applications, from solar collectors [24] to optoelectronic devices [25], sensors [21] to catalysts [20], and environmental applications [26] to medical applications [27].

Dyestuffs are organic pollutants which are widely used in textile, paper, printing industry and home paints, produced about $7 \times 10^{5}$ metric tons annually and sold in the market with more than 100.000 types [28, 29]. Wastewater containing dyes is one of the most problematic organic pollutants due to their high toxicity, suspended structures, and color. Reduction of light penetration as a result of coloring of dyes adversely affects activity for photosynthetic organisms in aquatic life [30-33]. However, it can be toxic to some living things in aquatic life, in the presence of aromatics, metals, chlorides, and so on [30-33]. Because of their synthetic origin and complex structure, dyes are stable and difficult to biologically degrade. Dyes can be classified as, anionic - direct, acid and reactive dyes; cationic - basic dyes; and nonionic - disperse dyes [30]. Among these, water-soluble reactive and acid dyes are the most problematic dyes [34, 35]. In addition, despite the low concentration of basic dyes, giving too much color with negatively affects water and water organisms $[36,37]$.

In this study, the prepared of isocyanurate based amine functionalized (PEI-TGIC) COFs were successfully synthesized in dimethyl formamide at $90{ }^{\circ} \mathrm{C}$. The prepared COFs were treated with $\mathrm{HCl}$ to protonation of amine groups on PEI-TGIC COFs. The PEI-TGIC COFs were characterized by using Fourier Transform Infrared (FT-IR) spectrometer, surface area and porosity measurements, zeta potential, and thermogravimetric analyzer (TGA) measurements. Moreover, the prepared PEI-TGIC based COFs were used as an absorbent for methyl orange removal from aqueous media.

\section{EXPERIMENTAL}

\subsection{Materials}

The branched polyethyleneimine (PEI, 50\% in water, Mn:1800, Aldrich) and triglycidyl isocyanurate (TGIC, Aldrich) were used for synthesis of covalent organic frameworks. 
Dimethyl formamide (DMF, 99\%, Merck) was used as solvent for COF synthesis. Hydrochloric acid ( $\mathrm{HCl}, 36.5 \%$, Sigma Aldrich) was used to protoation of PEI-TGIC COFs. Potassium chloride ( $\mathrm{KCl}, 99 \%$, Merck) was used for zeta potential measurements. Methyl orange (MO, ACS reagent, $85 \%$ dye content, Fluka) was used for absorption studies.

\subsection{Synthesis of PEI-TGIC covalent organic framework}

The synthesis of PEI-TGIC COF was carried out in DMF at $90{ }^{\circ} \mathrm{C}$ by using epoxy amine ring opening reaction [17]. In brief, $3.93 \mathrm{mmol}$ of TGIC was dissolved into $100 \mathrm{~mL}$ of DMF and $23.8 \mathrm{mmol}$ of PEI ( $2 \mathrm{~mL}$ of PEI solution \%50 in water), and stirred at $90{ }^{\circ} \mathrm{C}$, at 800 rpm mixing rate for $2 \mathrm{~h}$. The prepared PEI-TGIC COFs were precipitated in excess amount of acetone, and washed with acetone, acetone-water, water, and acetone again, to remove unreacted reactants. The prepared and washed PEI-TGIC COFs were dried by using heatgun and stored at closed tubes for further usage.

Moreover, the prepared PEI-TGIC COFs were treated with $1 \mathrm{M} \mathrm{HCl}$ acid to protonation of amine groups of to obtain higher positively charged PEI-TGIC COFs. Then, protonated PEITGIC (p-PEI-TGIC) COFs were washed with water once, acetone twice, and dried by using heat gun.

\subsection{Characterization of PEI-TGIC covalent organic framework}

Functional group determination of TGIC and PEI-TGIC COFswere carried out by Fourier Transform Infrared (FT-IR, Nicolet iS10, Thermo) spectroscopy with using attenuated total reflectance (ATR) module. The range of wavelength is in between 4000 and $650 \mathrm{~cm}^{-1}$.

The thermal behavior of PEI-TGIC and p-PEI-TGIC COFswere determined and comparedeach other with thermogravimetric analysis through using Thermogravimetric Analyzer (TGA, /DTA 6300, Exstar).Initially, moisture is removed from the sample through heating from $25^{\circ} \mathrm{C}$ to $100^{\circ} \mathrm{C}$. Then the temperature alteration is set to raise $10^{\circ} \mathrm{C}$ per minute from $90^{\circ} \mathrm{C}$ to $1000^{\circ} \mathrm{C}$.

Zeta Potential Analyzer (BIC, Brookhaven Inst. Corp.) is used for the determination of the particle charges. The aqueous solutions of PEI-TGIC and the p-PEI-TGIC COFwere diluted with $10^{-3} \mathrm{M} \mathrm{KCl}$ solution to prepare for analysis of zeta potential.

Particle size and shape are observed through using Scanning Electron Microscope (SEM, JEOL JSM-5600). The synthesized, washed and freeze-dried PEI-TGIC COFs were placed into carbon tape attachedaluminum stub and coated with gold to a few nanometer thicknesses under vacuum. The images were taken with an operating voltage of $20 \mathrm{kV}$.

Specific surface area, pore volume, and pore size determination of PEI-TGIC COF were carried out with Brunauer-Emmett-Teller (BET) and Barrett-Joyner-Halenda (BJH) methods by using Micrometritics, Tristrar II, Surface area and porosity device. Before analysis, the PEITGIC COF was dried in freeze-dryer (Christ Alpha 1-2 LD plus), and prior to measurementspassed through $\mathrm{N}_{2}$ gas for $8 \mathrm{~h}$ to remove moisture and other contaminants at 80 ${ }^{\circ} \mathrm{C}$ using a Flow Prep 060 Degasser.

\subsection{Absorption studies}

The absorption study of MO from aqueous solution was done by following literature with some modification [17]. For this purpose, $0.05 \mathrm{~g}$ of each PEI-TGIC and p-PEI-TGIC COFs were used as absorbents. Besides, the $100 \mathrm{~mL}$ of $250 \mathrm{ppm}$ MO aqueous solution were prepared and $0.05 \mathrm{~g}$ of each PEI-TGIC and p-PEI-TGIC COFs were added into solutions after taking zero time samples from solutions. Then, the samples from solution were taken in certain time intervals and were read by using UV-vis spectrophotometer (UV-Vis, T80+, PG Instruments) 
after 25 times dilution at $464 \mathrm{~nm}$ wavelength. The absorbed amount of $\mathrm{MO}$ dyes from prepared PEI-TGIC, and p-PEI-TGIC COFs were determined from the decreasing on absorbance values of diluted samples at $464 \mathrm{~nm}$ wavelength for MO.

\section{RESULTS AND DISCUSSION}

\subsection{Synthesis and characterization of PEI-TGIC COFs}

In recent years, the reactions of epoxy and amine groups are widely used for modification and synthesis of new polymeric structures [38]. In brief, the reaction involves the nucleophilic addition reaction of amine to epoxy groups [39]. The hydrogen atoms of primary and secondary amine groups provide to opening of oxirane ring of the epoxy components with nucleophilic addition reaction [40-42]. In here, the branched PEI molecules was used with the 1:2:1 ratio of primary, secondary, and tertiary amine groups content to reacted with tri epoxy groups contain TGIC molecule to synthesis of PEI-TGIC COFs. The molecular structure of PEI and TGIC, and schematic presentation of reaction between PEI and TGIC are given in Figure-1 (a). It was seen from Figure-1 (a), the amine primary and secondary amine groups on branched PEI molecule bonded with epoxy groups of TGIC with the nucleophilic addition reaction. On the other hand, the obtained optic microscope and SEM images are given in Figure- 1 (b).

Figure-1. (a) the schematic presentation of synthesis of PEI-TGIC COF, and (b) the optic microscope and SEM images of PEI-TGIC COFs.
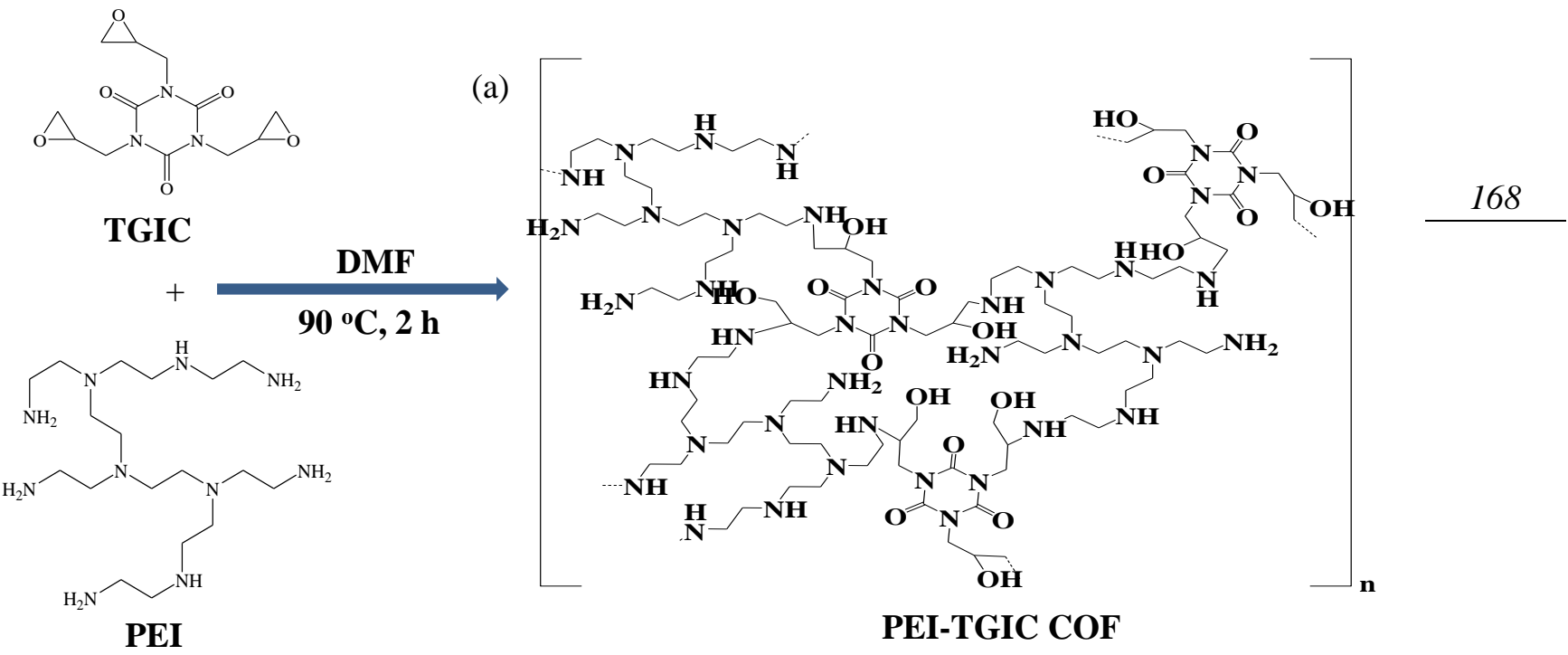

PEI-TGIC COF

(b)
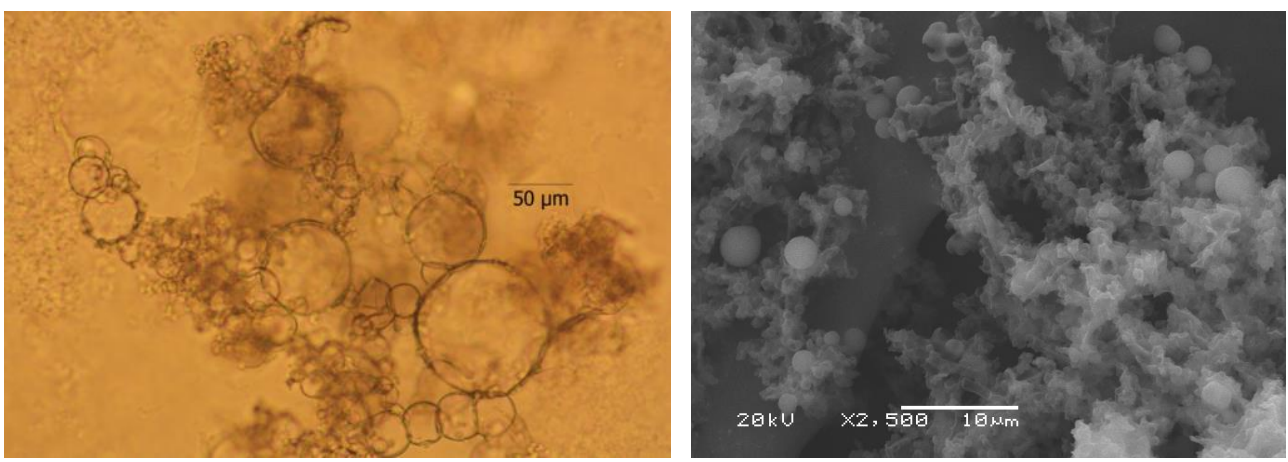

It was clearly seen from optic microscope and SEM images of PEI-TGIC COFs, the COFs are spherical shape with poly dispersed size ranges. The optic microscope images of PEITGIC COFs were taken from the aqueous solution of COFs, and it was seen that, the sizes of 
COFs between 20-100 $\mu \mathrm{m}$ in aqueous media, whereas the SEM images which are taken from dried from of PEI-TGIC COFs shown that the sizes of PEI-TGIC COFs are between 0.5-5 $\mu \mathrm{m}$. It can be said that, from optic microscope and SEM images the prepared PEI-TGIC COFs can be swollen easily in aqueous media with almost 20 fold increasing on size of dried from. On the other hand, the yield \% of reaction was gravimetrically calculated as $78 \pm 4.1 \%$ from the mass of reactant and product.

To confirm of synthesis of PEI-TGIC COF, the FT-IR spectrum of TGIC and PEI-TGIC were recorded and compared for the observing disappeared and appeared peaks after PEI-TGIC COF synthesis. It was clearly seen from Figure-2 (a), the FT-IR spectrum of TGIC shown some characteristic peaks such as $\mathrm{C}=\mathrm{O}$ stretching at $1677 \mathrm{~cm}^{-1}, \mathrm{CH}_{2}$ stretching at $1454 \mathrm{~cm}^{-1}, 1267$ $\mathrm{cm}^{-1}$ asymmetric epoxy ring stretching, $1148 \mathrm{~cm}^{-1} \mathrm{C}-\mathrm{N}-\mathrm{C}$ peak from aromatic ring, 988, and $840 \mathrm{~cm}^{-1}$ asymmetric epoxy ring bending, respectively. On the other hand, it was clearly seen that, the peaks from epoxy ring is disappeared and turned to $-\mathrm{OH}$ peaks at 1310 , and $1053 \mathrm{~cm}^{-}$ ${ }^{1}$, and the peaks from amine groups at $1590 \mathrm{~cm}^{-1}$ was also observed after synthesis PEI-TGIC COFs.

Figure- 2. (a) The FT-IR spectrum of TGIC and PEI-TGIC COF, and (b), $\mathrm{N}_{2}$ adsorption/desorption graph of PEI-TGIC COF.
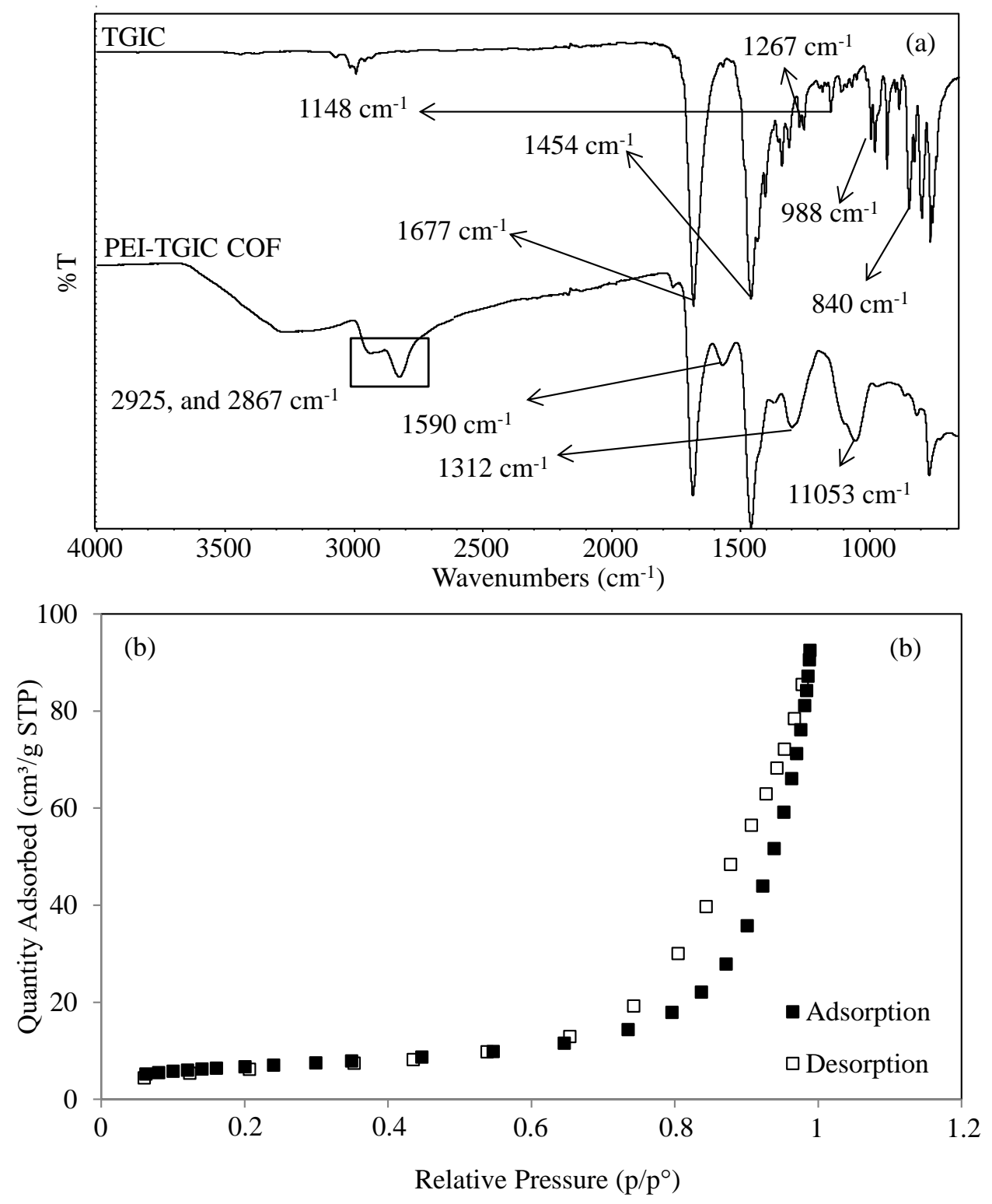
Besides, the surface area, pore size and pore volume values of PEI-TGIC COFs were determined by using $\mathrm{N}_{2}$ absorption/desorption measurements and corresponding graph is given in Figure 2 (b). The shape of obtained hysteresis loop were H3, and it H3 type hysteresis loopindicated that the narrow slit-shaped pores were obtained in prepared PEI-TGIC COFs [43, 44]. Moreover, the surface area was determined as $23.4 \mathrm{~m}^{2} / \mathrm{g}$ from $\mathrm{N}_{2}$ absorption/desorption measurements of PEI-TGIC COFs with using BET method. Also, the pore volume and pore size values of PEI-TGIC COFs were determined as $0.142 \mathrm{~cm} 3 / \mathrm{g}$, and $22.5 \mathrm{~nm}$, respectively, from $\mathrm{N}_{2}$ absorption/desorption measurements of PEI-TGIC COFs with using BJH method. The porous structure of prepared provides a considerable number of reactive sites on PEI-TGIC COFs.

Besides, the prepared PEI-TGIC COFs were treated with $100 \mathrm{~mL}$ of $1 \mathrm{M} \mathrm{HCl}$ at room temperature about $2 \mathrm{~h}$ to protonate amine groups. The change on surface charges were determined by using zeta potential measurements and corresponding graph is given in Figure 3 (a). It was observed that, the surface charge of PEI-TGIC COF is determined as $+18.3 \pm 1.7 \mathrm{mV}$, whereas increased to $+46.1 \pm 2.6 \mathrm{mV}$ after $\mathrm{HCl}$ treated to prepare p-PEI-TGIC COF. The increasing on surface charges approximately 2.5 fold confirm that the amine groups of PEITGIC COF was successfully protonated.

Figure- 3. The changing on (a) surface charges, and (b) thermal stability of PEI-TGIC after protonation.
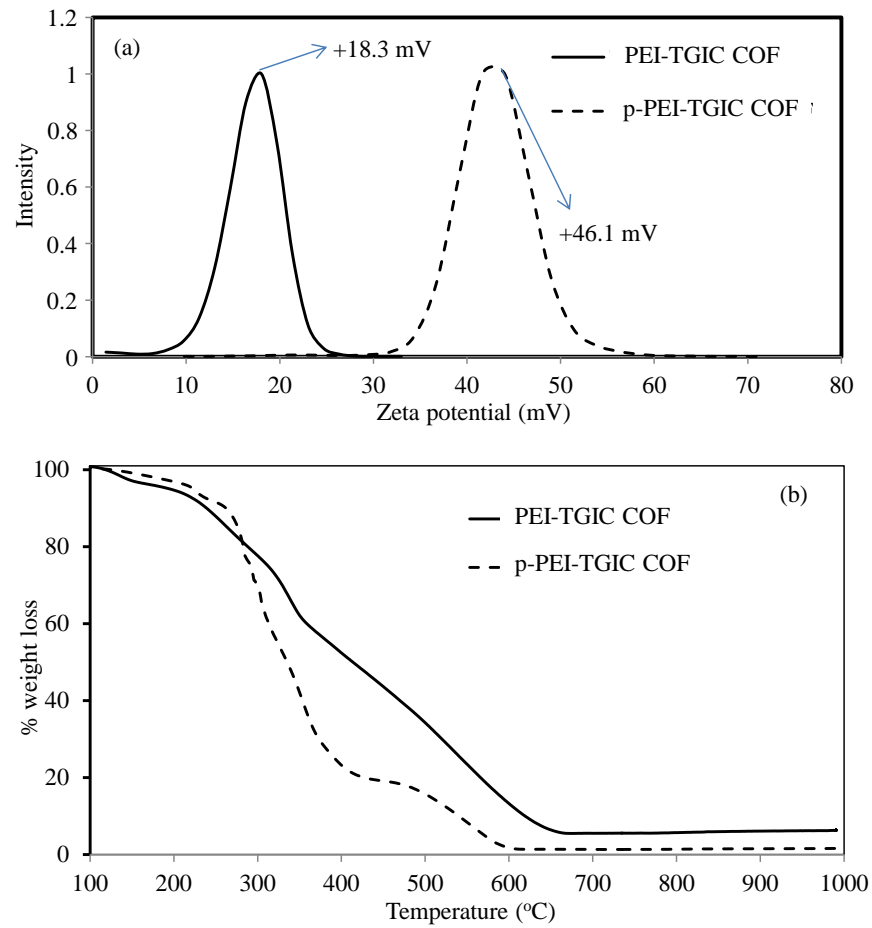

Furthermore, the thermal stability of PEI-TGIC, and p-PEI-TGIC COFs were compared each other from their corresponding TGA thermograms in Figure 3 (b). The bare PEI-TGIC COFs shown three degradation steps as started for first degradation step is between $100-154{ }^{\circ} \mathrm{C}$ with $3.2 \%$ weight loss, the second degradation step is between $213-326^{\circ} \mathrm{C}$ with $30.7 \%$ weight loss, and the last degradation step between $350-611^{\circ} \mathrm{C}$ with $93.6 \%$ weight loss, and finally the $93.7 \%$ weight loss was observed at $1000{ }^{\circ} \mathrm{C}$. Differently from bare form of PEI-TGIC, the pPEI-TGIC COFs shown lower thermal stability in three degradation steps as observing of the first degradation step is between $100-228{ }^{\circ} \mathrm{C}$ with $2 \%$ weight loss, the second degradation step I between $258-405{ }^{\circ} \mathrm{C}$ with $80.6 \%$ weight loss, and the third degradation step is between 473 $602{ }^{\circ} \mathrm{C}$ with $98.4 \%$ weight loss, whereas it was observed $98.6 \%$ weight loss at $1000{ }^{\circ} \mathrm{C}$, respectively. 


\subsection{The potential usage of PEI-TGIC COFs as an absorbent}

In literature, there is so many publication has been reported about removing of toxic organic dyes such as oxidation, reduction, and absorption/desorption or organic dyes [45-47]. The oxidation or reduction of organic dyes has some disadvantages such as using some catalysts as metal nanoparticles, or extinguishment of reusability potentiality of dyes. On the other hand, the absorption or desorption of organic dyes from waste waters provide reusability potentiality of organic dyes with desorption processes. Therefore, the potential usage of prepared PEI-TGIC and p-PEI-TGIC COFs were investigated for $\mathrm{MO}$ dyes from aqueous media. The absorption of MO studies was carried out from $100 \mathrm{~mL} 250 \mathrm{ppm}$ MO solution with the addition of $0.05 \mathrm{~g}$ of PEI-TGIC and p-PEI-TGIC COFs. The absorbed amount of MO was calculated by reading of the taken samples from MO solution in certain time intervals with UV-Vis spectrometer at 464 $\mathrm{nm}$ wavelength for MO dyes. The samples were 25 times diluted before reading on UV-Vis spectrometer. The corresponding graph is given in Figure 4 (a). It was observed from Figure4 (a) that, the PEI-TGIC COFs were absorbed $56.4 \pm 26 \mathrm{mg} / \mathrm{g}$ MO in $5 \mathrm{~min}$, and $156.6 \pm 4.9 \mathrm{mg} / \mathrm{g}$ MO dyes from aqueous media in $30 \mathrm{~min}$ (in equilibrium). On the other hand, the absorbed amount of MO by p-PEI-TGIC was determined as $177.6 \pm 6.3 \mathrm{mg} / \mathrm{g}$ in $5 \mathrm{~min}$, and $202.4 \pm 4.3$ $\mathrm{mg} / \mathrm{g}$ in $30 \mathrm{~min}$. It was observed that, the rate of absorption and amount of absorbed MO higher for p-PEI-TGIC COFs than bare PEI-TGIC COFs, due to higher positive surface charges of $\mathrm{p}$ PEI-TGIC interactions with negatively charged MO dyes.

Figure- 4. (a) The adsorption graph of PEI-TGIC, and p-PEI-TGIC COFs MO dyes [0.05 g COF, $100 \mathrm{ml}, 250 \mathrm{ppm} \mathrm{MO}$ ], and (b) digital camera images of PEI-TGIC, and p-PEITGIC COFs and theri MO absorbed forms.
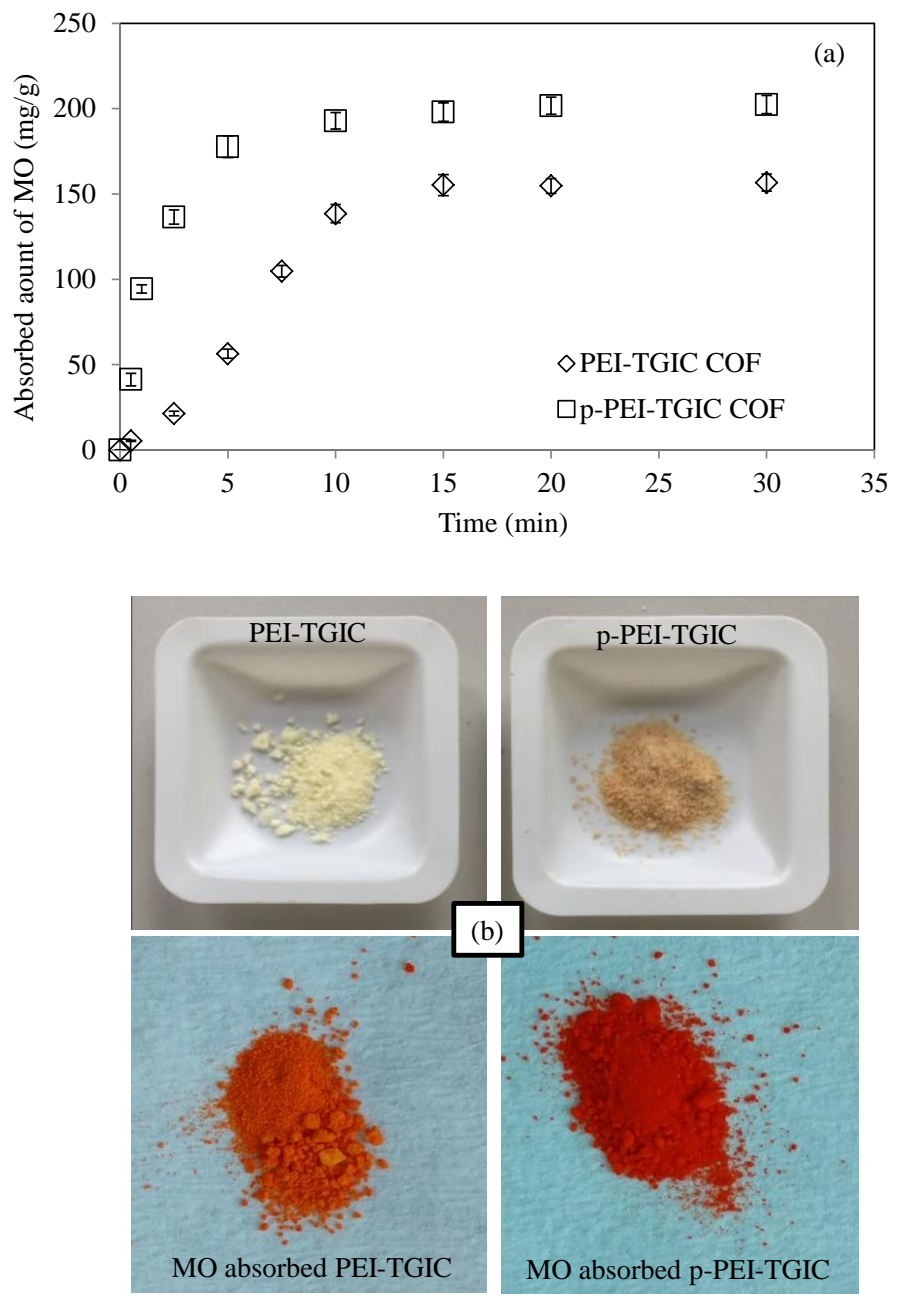
The digital camera images of PEI-TGIC, p-PEI-TGIC and their corresponding MO absorbed forms are also given in Figure- 4 (b). It was clearly seen that, the white color of PEITGIC COFs turned to brownish color after $\mathrm{HCl}$ treatment, and also the orange color of $\mathrm{MO}$ absorbed form of p-PEI-TGIC COFs darker then PEI-TGIC COFs that confirm that higher amount absorption of MO dyes by p-PEI-TGIC COFs.

The absorption kinetic of MO by PEI-TGIC and p-PEI-TGIC COFs were determined by using well-knownpseudo-first-order (Eq. 1), and pseudo-second-order (Eq. 2) models, respectively following corresponding equations [48];

$$
\begin{aligned}
& \log \left(\mathrm{q}_{\mathrm{e}}-\mathrm{q}_{\mathrm{t}}\right)=\log \mathrm{Q}_{\mathrm{t}}-\left(\mathrm{k}_{1} / 2.303\right) \mathrm{t} \\
& \mathrm{t} / \mathrm{q}_{\mathrm{t}}=1 / \mathrm{k}_{2} \mathrm{q}_{\mathrm{e}}{ }^{2}+\mathrm{t} / \mathrm{q}_{\mathrm{e}}
\end{aligned}
$$

where; "qe" is absorbed amount of molecule at equilibrium $(\mathrm{mg} / \mathrm{g})$, "qt" isabsorbed amount of molecule at at time $(\mathrm{mg} / \mathrm{g}), \mathrm{k}_{1}$ is rate constant for pseudo-first-order model (min-1), and $\mathrm{k}_{2}$ is constant for pseudo-second-order model $\left(\mathrm{g} \cdot \mathrm{mg}^{-1} \cdot \mathrm{min}\right)$. The calculated values of qe, $\mathrm{k}_{1}$ and $\mathrm{k}_{2}$ values from the plots of $\log \left(\mathrm{q}_{\mathrm{e}}-\mathrm{q}_{\mathrm{t}}\right)$ vs $\mathrm{t}$ for pseudo-first-order model, and $\mathrm{t} / \mathrm{q}_{\mathrm{t}} \mathrm{vs} \mathrm{t}$ fro pseudo-second-order model, are summarized in Table 1 for MO absorption by PEI-TGIC, and p-PEI-TGIC COFs, respectively. It was observed for MO absorption by PEI-TGIC COFs that, $210.6 \mathrm{mg} / \mathrm{g}$ and $333.3 \mathrm{mg} / \mathrm{g} \mathrm{q}$ values for pseudo-first-order, and pseudo-second-order kinetic models, whereas experimental $\mathrm{q}_{\mathrm{e}}$ value is $156.6 \pm 4.9 \mathrm{mg} / \mathrm{g}$. Moreover, the $\mathrm{k}_{1}$, and $\mathrm{k}_{2}$ values were also determined as $0.227 \mathrm{~min}^{-1}$, and $1 \times 10^{-4}$ g.min-1.min, with 0.971 , and 0.584 corelation coefficient $\left(\mathrm{R}^{2}\right)$ values for pseudo-first-order, and pseudo-second-order kinetic models, respectively.

Table- 1. Pseudo-first-order and pseudo-second-order constants and correlation coefficients for adsorption of MO by PEI-TGIC, and p-PEI-TGIC COFs.

\begin{tabular}{|c|c|c|c|c|c|c|c|}
\hline \multirow{2}{*}{ Material } & Exp. & \multicolumn{2}{|c|}{ Pseudo-first-order-model } & \multicolumn{3}{|c|}{ Pseudo-second-order-model } \\
\cline { 2 - 8 } & $\mathrm{q}_{\mathrm{e}}(\mathrm{mg} / \mathrm{g})$ & $\begin{array}{c}\mathrm{k}_{1} \\
\left(\mathrm{~min}^{-1}\right)\end{array}$ & $\begin{array}{c}\mathrm{q}_{\mathrm{e}} \\
(\mathrm{mg} / \mathrm{g})\end{array}$ & $\mathrm{R}^{2}$ & $\begin{array}{c}\mathrm{k}_{2} \\
\left(\mathrm{~g} \mathrm{mg}^{-1} \mathrm{~min}\right)\end{array}$ & $\begin{array}{c}\mathrm{q}_{\mathrm{e}} \\
(\mathrm{mg} / \mathrm{g})\end{array}$ & $\mathrm{R}^{2}$ \\
\hline PEI-TGIC COF & $156.6 \pm 4.9$ & 0.227 & 210.6 & 0.971 & $1 \times 10^{-4}$ & 333.3 & 0.584 \\
\hline p-PEI-TGIC COF & $202.4 \pm 5.3$ & 0.264 & 149.7 & 0.978 & $3 \times 10^{-3}$ & 217.4 & 0.998 \\
\hline
\end{tabular}

It can be said that from results, the MO absorption by PEI-TGIC COFs fitting with pseudo-first-order kinetic model. On the other hand, the absorption of MO by p-PEI-TGIC COFs $\mathrm{q}_{\mathrm{e}}$ values were calculated as 149.7 , and $2017.4 \mathrm{mg} / \mathrm{g}$ forpseudo-first-order, and pseudosecond-order kinetic models, whereas experimental $\mathrm{q}_{\mathrm{e}}$ value is $202.4 \pm 5.3 \mathrm{mg} / \mathrm{g}$. The $\mathrm{R}^{2}$ values with 0.978 , and $0.998, \mathrm{k}_{1}$ and $\mathrm{k}_{2}$ values with $0.264 \mathrm{~min}^{-1}$, and $3 \times 10^{-3} \mathrm{~g} \cdot \mathrm{min}-1$.min were calculated forpseudo-first-order, and pseudo-second-order kinetic models, respectively. It was observed that, the MO absorption by p-PEI-TGIC COFs fitting with pseudo-second-order kinetic model.

The validity of kinetic model can be done from R2 values, and also the Sum of Square Error (SSE \%) were also used in literature from the corresponding equation (Eq. 3) [48];

$$
\operatorname{SSE} \%=\left(\Sigma\left(\mathrm{q}_{\mathrm{e}, \mathrm{exp}}-\mathrm{q}_{\mathrm{e}, \mathrm{cal}}\right)^{2} / \mathrm{N}\right)^{1 / 2}
$$

Where, "N" is the number of data points. "q,exp" and "q $\mathrm{q}_{\mathrm{e}, \mathrm{cal}}$ " $(\mathrm{mg} / \mathrm{g})$ are the experimental and calculated adsorption capacities, respectively. The numerical fitting is good if $\mathrm{R}^{2}$ is $\sim 1.0$ and SSE is $\sim 0.0$. The SSE values were calculated as 18 and 58.9 for pseudo-first-order, and 
pseudo-second-order kinetic models for MO absorption by p-PEI-TGIC, and 17.6, and 5 for pseudo-first-order, and pseudo-second-order kinetic models for MO absorption by p-PEI-TGIC COFs. The validity of fitted kinetic models of MO absortion by PEI-TGIC, and p-PEI-TGIC COFs were proven with SSE calculation.

\section{CONCLUSION}

In this study, it was reported that, the synthesis of novel spherical shape, porous PEITGIC COFs with $23.4 \mathrm{~m}^{2} / \mathrm{g}$ surface area, $0.143 \mathrm{~cm}^{3} / \mathrm{g}$ pore volume, and $22.5 \mathrm{~nm}$ pore size, and its protonated form p-PEI-TGIC COFs were successfully carried out. The surface charge increased to $46.1 \pm 2.6 \mathrm{mV}$ from $18.1 \pm 1.7$ with the protonation of PEI-TGIC COFs. The prepared PEI-TGIC and p-PEI-TGIC COFs absorbed $156.6 \pm 4.9 \mathrm{mg} / \mathrm{g}$, and $202.4 \pm 5.3 \mathrm{mg} / \mathrm{g}$ MO from its aqueous solution. On the other hand, the absorption kinetic of MO by PEI-TGIC COFs fitted with pseudo-first-order model with $0.971 \mathrm{R}^{2}$ values, whereas absorption kinetic of MO by $\mathrm{p}$ PEI-TGIC COFs fitted with pseudo-second-order model with $0.998 \mathrm{R}^{2}$ values. Therefore, the cationic-based COFs of PEI-TGIC and p-PEI-TGIC have great potential for the removal of negatively charged dyes, pesticides, herbicides, and heavy toxic metal ions different oxidation states from aquatic environments.

\section{Conflict of Interest Statement}

The authors declare no conflict of financial, academic, commercial, political, or personal interests

\section{Acknowledgements}

The authors are grateful for the financial support by Canakkale Onsekiz Mart University Scientific Research Commission (FBA-2016-727). 


\section{REFERENCES}

[1] THOMAS, A. 2010, Functional materials: from hard to soft porous frameworks. Angew. Chem. Int. Ed., 49, 8328.

[2] ZAYED, J.M., NOUVEL, N., RAUWALD, U., SCHERMAN, O.A. 2010, Chemical complexity - supramolecular self-assembly of synthetic and biological building blocks in water. Chem. Soc. Rev., 39, 2806.

[3] DING, S.Y. WANG, W. 2013, Covalent organic frameworks (COFs): from design to applications. Chem. Soc. Rev., 42, 548

[4] FUJITA, M. YAZAKI, J. OGURA, K. 1990, Preparation of a macrocyclicpolynuclear complex, [(en)Pd(4,4'-bpy)]4(NO3)8 (en = ethylenediamine, bpy = bipyridine), which recognizes an organic molecule in aqueous media. J. Am. Chem. Soc., 112, 5645.

[5] Special issues for metal organic frameworks: Chem. Soc. Rev., 2009, 38, 1201; Chem. Rev., 2012, 112, 673.

[6] GREIM, J., SCHWETZ, K., BORON CARBIDE, A. 2006, Boron Nitride, and Metal Borides; Ullmann's Encyclopedia of Industrial Chemistry, Wiley-VCH Verlag GmbH \& Co. KGaA,

[7] CO^TE', A.P. BENIN, A. I. OCKWIG, N. W.'KEEFFE, M. O MATZGER, A. J. YAGHI, O. M. 2005, Porous, crystalline, covalent organic frameworks. Science, 310, 1166.

[8] MCCRUM, N.G., BUCKLEY, C.P., BUCKNALL, C.B. 1997, Principles of polymer engineering, Oxford University Press, New York,

[9] DAVIS, M.E. 2002, Ordered porous materials for emerging applications. Nature, , 417, 813.

[10] BLAKE, A.J., CHAMPNESS, N.R., CREW, M., PARSONS, S. 1999,Sawhorse connections in a $\operatorname{Ag}(\mathrm{I})$-nitrite coordination network: $\{[\operatorname{Ag}($ pyrazine $)] \mathrm{NO} 2\} \propto$. New J. Chem., 23, 13.

[11] DAWSON, R., COOPER, A.I., ADAMS D.J. 2011, Nanoporous organic polymer networks. Prog.Polym.Sci., 37, 530.

[12] TONG, M.L. YU, X.L., CHEN, X.M., YU X.L., MAK, T.C.W. 1998, A novel twodimensional rectangular network. Synthesis and structure of $\left\{\left[\mathrm{Cu}\left(4,4^{\prime}-\right.\right.\right.$ bpy $)($ pyz $)(\mathrm{H} 2 \mathrm{O}) 2][\mathrm{PF} 6] 2\}$ n $\left(4,4^{\prime}\right.$-bpy = 4,4'-bipyridine, pyz = pyrazine $) . J$. Chem. Soc. Dalton Trans., 5.

[13] COOPER, A.I. 2009. Conjugated Microporous Polymers. Adv. Mater., 21, 1291.

[14] TAN, L., TAN, B. 2017, Hypercrosslinked porous polymer materials: design, synthesis, and applications. Chem. Soc. Rev., 46, 3322.

[15] ROBESON, L.M., DOSE, M.E., FREEMAN, B.D., PAUL, D.R., 2017, Analysis of the transport properties of thermally rearranged (TR) polymers and polymers of intrinsic microporosity (PIM) relative to upper bound performance. J. Memb. Sci., 525, 18.

[16] SPRICK, R.S., BONILLO, B., SACHS, M., CLOWES, R.,. DURRANT, J.R, ADAMS, D.J., COOPER, A.I. 2012, Special issues for metal organic frameworks: Chem. Soc. Rev., 2009, 38, 1201; Chem. Rev., 112, 673. Extended conjugated microporous polymers for photocatalytic hydrogen evolution from water.Chem. Comm., 2016, 52, 10008.

[17] SAHINER, N., DEMIRCI, S. 2016, Poly ionic liquid cryogel of polyethyleneimine: Synthesis, characterization, and testing in absorption studies. J. Appl. Polym. Sci., 133, 43478. 
[18] BEN, T., REN, H., MA, S., CAO, D., LAN, J., JING, X., WANG, W., XU, J., DENG, F., SIMMONS, J.M., QIU, S., ZHU, G. 2009, argeted synthesis of a porous aromatic framework with high stability and exceptionally high surface area. Angew.Chem., Int. Ed., 48, 9457.

[19] MALY, K.E. 2009, Assembly of nanoporous organic materials from molecular building blocks. J. Mater. Chem., 19, 1781.

[20] SAHINER, N., DEMIRCI, S., SEL, K. 2016, Covalent organic framework based on melamine and dibromoalkanes for versatile use. J. Porous Mater., 23, 105.

[21] SAHINER, N., DEMIRCI, S. 2019, The use of covalent organic frameworks as template for conductive polymer synthesis and their sensor applications. J. Porous Mater., 26, 481.

[22] LI, Z., ZHI, Y., FENG, Z., DING, X., ZOU, Y., LIU, X., MU, AN AZINE Y., 2015, Linked Covalent Organic Framework: Synthesis, Characterization and Efficient Gas Storage. Chem. Eur. J., , 21, 12079.

[23] BISWAL, B.P., CHAUDHARI, H.D., BANERJEE, R., KHARUL, U.K. 2016, Chemically stable covalent organic framework (COF), polybenzimidazole hybrid membranes: enhanced gas separation through pore modulation. Chem. Eur. J., 22, 4695.

[24] RAZAVI S.H., AHMADI R., ZAHEDI A., 2019, Modeling, simulation and dynamic control of solar assisted ground source heat pump to provide heating load and DHW. Appl. Therm. Eng., , 128, 127.

[25] MANDAL, A.K., MAHMOD, J., BAEK, J. B, 2017,Two, Dimensional Covalent Organic Frameworks for Optoelectronics and Energy Storage. Chem Nano Mat., 3, 373.

[26] BOBBITT, N.S. MENDONCA M.L., HOWARTH A.J., ISLAMOGLU T., HUPP J.T., FARHA O.K., SNURR R.Q. 2017, Metal-organic frameworks for the removal of toxic industrial chemicals and chemical warfare agents. Chem. Soc. Rev., 46, 3357.

[27] BAI, L. PHUA S.Z.F., LIM W.Q., JANA A., LUO Z., THAM H.P., ZHO L., GAO Q., ZHAO Y. 2016, Nanoscale covalent organic frameworks as smart carriers for drug delivery. Chem. Comm., 52, 4128.

[28]. CLARKE, E.A.R. 1980, vol. 3, part A. New York: Springer-Verlag, p. 181.

[29] ZOLLINGER, H. 1987, Azo dyes and pigments. Colour chemistry-synthesis, properties and applications of organic dyes and pigments. New York: VCH,. p. 92.

[30] MISHRA, G., TRIPATHY, M., 1993, A critical review or the treatments for decolourisation of textle effluent. Colourage, 40, 35.

[31] BANAT, I.M., NIGAM, P., SINGH, D., MARCHANT, R. 1996, Microbial decolourization of textile-dye-containing effluents: A review. Bioresour. Technol., 58, 217.

[32] FU, Y., VIRARAGHAVAN, T. 2001, Fungal decolorization of dye wastewaters: a review. Bioresour. Technol., 79, 251.

[33] ROBINSON, T., MCMULLAN, G., MARCHANT, R., NIGAM, P. 2001, Remediation of dyes in textile effluent: a critical review on current treatment technologies with a proposed alternative. Bioresour.Technol., 77, 247.

[34] KARCHER, S., KORNMULLER, A., JEKEL, M. 1999. Removal of Reactive Dyes by Sorption/Complexation with Cucurbituril, Water Sci. Technol., 40, 425. 
[35] SUMATHI, S., MANJU, B.S, 2000, Uptake of reactive textile dyes by Aspergillus foetidus. Enzyme Microbial.Technol., 27, 347.

[36] MITTAL A.K., GUPTA S.K. 1996, Biosorption of cationic dyes by dead macro fungus fomitopsiscarnea: batch studies.Water Sci. Technol., 34, 157.

[37] FU, Y., VIRARAGHAVAN, T. 2002, Removal of Congo Red from an aqueous solution by fungus Aspergillusniger. Adv. Environ. Res., 7, 239.

[38] FRANCOS, X.F., 2014, Theoretical modeling of the effect of proton donors and regeneration reactions in the network build-up of epoxy thermosets using tertiary amines as initiators. Eur. Polym. J., 55, 35.

[39] ZVETKOV, V.L., KRASTEV, R.K, SAMICHKOV, V.I. 2008, Rate equations in the study of the DSC kinetics of epoxy-amine reactions in an excess of epoxy. Thermochim. Acta, 478, 17.

[40] MIJOVIC, J., ANDJELIC S., WINNIE YEE C.F., BELLUCCI F, NICOLAIS L., 1995, A Study of Reaction Kinetics by Near-Infrared Spectroscopy. 2. Comparison with Dielectric Spectroscopy of Model and Multifunctional Epoxy/Amine Systems.Macromolecules, 28, 2797.

[41] MIJOVIC, J., FISHBAIN A., WIJAYA J. 1992, Mechanistic modeling of epoxy-amine kinetics. 1. Model compound study. Macromolecules, 25, 979.

[42] MIJOVIC, J., FISHBAIN, A., WIJAYA, J. 1992, Mechanistic modeling of epoxy-amine kinetics. 2. Comparison of kinetics in thermal and microwave fields. Macromolecules, $25,986$.

[43] ZHANG, Z., ZHANG, Y.J., LU, L.H., SI, Y.J., ZHANG, S., CHEN, Y., DAI, K., DUAN P., DUAN, L.M., LIU, J.H. 2017, Graphitic carbon nitride nanosheet for photocatalytic hydrogen production: The impact of morphology and element composition. Appl. Surf.Sci., 391, 369.

[44] DONG, F., LI, Y.H., HO, W.K., ZHANG, H.D., FU, M., WU, Z.B. 2014, Synthesis of mesoporous polymeric carbon nitride exhibiting enhanced and durable visible light photocatalytic performance. Chin. Sci. Bull., 59, 688.

[45] KIM, T.H., PARK, C., YANG, J., KIM, S. 2004, Comparison of disperse and reactive dye removals by chemical coagulation and Fenton oxidation. J. Hazard. Mater., 112, 95.

[46] AJMAL, M., DEMIRCI, S., SIDDIQ, M., AKTAS, N., SAHINER, N. 2016, Simultaneous catalytic degradation/reduction of multiple organic compounds by modifiable $\mathrm{p}$ (methacrylic acid-co-acrylonitrile)-M (M: $\mathrm{Cu}, \mathrm{Co}$ ) microgel catalyst composites. New J. Chem., 40, 1485.

[47] PAUlinO A.T., GUILHERME M.R., REIS A.V., CAMPESE G.M., MUNIZ E.C, NOZAKI, J. 2006, Removal of methylene blue dye from an aqueous media using superabsorbent hydrogel supported on modified polysaccharide. J. Coll. Inter. Sci., 301, 55.

[48] HABEEB, O.A., KANTHASAMY, R., ALI, G.A.M., YUNUS R.B.M.,. OLALERE O.A. 2017, Kinetic, isotherm and equilibrium study of adsorption of hydrogen sulfide from wastewaters using modified eggshells. IIUM Eng. J. 18, 1. 